\title{
La subversión tecnológica de la vida cotidiana. Un análisis desde el pensamiento complejo de Morin
}

\author{
Richard Priscal Palacios \\ Multiversidad Mundo Real Edgar Morin \\ richardpriscal@montevideo.com.uy
}

\section{RESUMEN}

La cultura de consumo global como modelo vertebrador del mundo actual ha generado notorias transformaciones en sociedades globales organizadas de acuerdo a los parámetros centrales del hiperconsumo y la hiperconectividad. La influencia de las tecnologías ha colonizado gran parte de la vida privada de las personas y están siendo importantes en los estilos de vida hegemónicos, perpetuando la fascinación por los distintos dispositivos tecnológicos existentes. Desde la perspectiva del pensamiento complejo y como propósito central esta indagación busca explicaciones más globales sobre los impactos biopsico-sociales del consumo en los entornos virtuales. Esta indagación se propone conocer, describir y comprender la complejidad de las nuevas prácticas de consumo en los nuevos entornos virtuales. Centrada en una metodología de tipo documental y de acuerdo a una profunda revisión bibliográfica y hemerográfica este artículo ofrece nuevas miradas para la comprensión de un tema complejo y multidimensional. En el actual proceso de hibridación entre los seres humanos y las máquinas se están generando transformaciones importantes en la condición humana, en las relaciones humanas y en el modelo de familia. La hiperconectividad tecnológica ha reforzado la mercantilización de la vida y la cultura del desecho como dimensiones centrales de la vida cotidiana.

Palabras clave: cultura de consumo global; hiperconectividad; subversión tecnológica; hiperconsumo; pensamiento complejo. 


\title{
The technological subversion of everyday life. An analysis from
}

\section{Morin's complex thinking}

\begin{abstract}
The culture of global consumption as the backbone model of the current world has generated notorious transformations in global societies organized according to the central parameters of hyperconsumption and hyperconnectivity. The influence of technologies has colonized a large part of people's private lives and they are being important in hegemonic lifestyles, perpetuating the fascination for the different existing technological devices. From the perspective of complex thinking and as a central purpose, this inquiry seeks more global explanations about the biopsychosocial impacts of consumption in virtual environments. This inquiry aims to know, describe and understand the complexity of new consumer practices in new virtual environments. Focused on a documentary-type methodology and according to a thorough bibliographic and hemerographic review, this article offers new perspectives for the understanding of a complex and multidimensional issue. In the current process of hybridization between human beings and machines, important transformations are being generated in the human condition, in human relationships and in the family model. Technological hyperconnectivity has reinforced the commodification of life and the culture of waste as central dimensions of everyday life.
\end{abstract}

Keywords: global consumer culture; hyperconnectivity; technological subversion; hyperconsumption; complex thinking.

Artículo recibido: 05 ene. 2021 Aceptado para publicación: 06 feb. 2021 Correspondencia: richardpriscal@montevideo.com.uy Conflictos de Interés: Ninguna que declarar 


\section{INTRODUCCIÓN}

La cultura de consumo global como sistema vertebrador de las actuales sociedades ha generado profundas y multidimensionales transformaciones en la vida cotidiana. El modelo alimentario agroindustrial, el hiperconsumo, la dependencia tecnológica y la cultura del desecho como dimensiones centrales de la vida cotidiana orientan la vida de millones de personas en el mundo entero.

La cultura de consumo global como máxima expresión de la omnipresente cultura mundo ha instalado la idea de que el consumo es la herramienta por excelencia para alcanzar el bienestar individual y la buena vida. La civilización del consumo ha subvertido totalmente la vida cotidiana y ha profundizado especialmente un consumo tecnológico que ha cambiado sustancialmente la vida en el planeta.

Diversas perspectivas teóricas han expresado que la cultura de consumo global ha extendido la idea de que todo es objeto de consumo lo que ha profundizado la mercantilización de la vida, el desarrollo de la hiperconectividad y la cultura del desecho. Caracteriza a las sociedades de consumo la figura del usuario-cyborg definido por la fascinación tecnofílica, la claustrofilia y la hiperconectividad como valores centrales de su vida cotidiana. En este marco la cultura de consumo global ha profundizado el consumo y extendido la vigilia en un mundo pensado para el ocio y el entretenimiento.

Desde la perspectiva del pensamiento complejo y como propósito central esta indagación busca explicaciones más globales sobre los impactos bio-psico-sociales que la cultura tecnológica está teniendo en la vida cotidiana. A su vez, este trabajo pretende conocer, describir y comprender las nuevas prácticas de consumo en los entornos virtuales.

La comprensión de la cultura de consumo global y la subversión tecnológica de la vida cotidiana desde la perspectiva del pensamiento complejo permite relacionar todo un entramado de situaciones e interacciones que desde el paradigma simplificador clásico se encontraban compartimentadas y acotadas a explicaciones insuficientes de la realidad. Poder comprender la coexistencia de múltiples interpretaciones sobre este tema es imprescindible para también mostrar las distintas formas de vivir en el imperio de la cultura de consumo global. 
Problematizar sobre un modelo cultural que se sustenta en el consumismo y la cultura del desecho como esquema organizador de la vida es asumir éticamente una mejor comprensión de los problemas globales.

Desde una perspectiva relacional, se considera pertinente visualizar de qué manera la cultura de consumo global influye en las prácticas de consumo de las sociedades globales y refuerza el rol de los entornos virtuales como dispositivos disciplinantes. Es imprescindible generar una conciencia crítica que visibilice en qué medida la cultura de consumo global, mediante sus dispositivos de disciplinamiento cultural, orienta la construcción de prácticas de consumo hacia una cultura del desecho, cuya centralidad expresa que absolutamente todo puede ser objeto de consumo y de descarte, erosionando, de esta forma, un modelo de sociedad sustentado en el consumo responsable.

\section{ESTRATEGIAS METODOLÓGICAS}

Esta indagación de carácter cualitativo tiene como propósito la revisión de conceptos y categorías que den cuenta del hiperconsumo en los entornos virtuales en el contexto de las actuales sociedades latinoamericanas.

Centrada en una metodología de tipo documental, estará orientada por la perspectiva del pensamiento complejo para la identificación y construcción de categorías que hagan visible el multidimensional universo de la cultura de consumo en los entornos virtuales. Estará sustentada en la idea de pensar en términos organizacionales, relacionales e integradores a la vez que intentará traducir la complejidad de la realidad sin separar el objeto-sistema de su entorno, ni de nuestra mirada cognoscente.

Esta investigación está basada en una profunda revisión bibliográfica y hemerográfica que da cuenta del estado del conocimiento referente a la cultura de consumo global y permite la construcción de nuevas perspectivas para pensar abordajes en relación con los impactos y con las sinergias que tienen lugar a partir del consumo en los entornos virtuales. La recopilación de datos permitirá la categorización de contenidos y el establecimiento de nuevas perspectivas sobre la realidad estudiada.

La perspectiva del pensamiento complejo de Morin permite una nueva mirada sobre el consumo en los entornos virtuales que habilita a que el tema sea revisado, debatido y problematizado de acuerdo a nuevos parámetros epistemológicos. La superación de las parcelaciones disciplinares y culturales son importantes para que se hagan visibles las 
rupturas, las continuidades, las tensiones, las contradicciones y las hibridaciones presentes en el objeto de estudio.

Desde el paradigma complejo de Morin (1999a, 1999b, 2003, 2011) la cultura de consumo global y las nuevas prácticas de consumo en los entornos virtuales pueden verse como un sistema multidimensional en el que sus elementos constitutivos se presentan como partes de un tejido dinámico y complejo. Es pertinente pensar en la cultura de consumo como una globalidad sistémica, abierta, histórica y contextualizada lo que habilita a pensar en un objeto relacional y cambiante.

La intertextualidad como recurso para el dialogo de las distintas visiones teóricas presentes en este trabajo promoverá la reflexión dialógica y la construcción de explicaciones más ricas y globales sobre las dimensiones centrales de una cultura de consumo global que gracias a los múltiples dispositivos y artefactos tecnológicos existentes ha subvertido drásticamente la vida cotidiana.

\section{RESULTADOS Y DISCUSIÓN}

Señala Castells (2000) que los medios de comunicación en las décadas posteriores a la segunda guerra mundial han tenido un papel relevante en la conformación de la cultura y como instrumento de propaganda.

En la segunda mitad del siglo XX se diseña toda una cultura del pensamiento único a través de una serie de dispositivos e instituciones que exportaron todo un sistema de valores hegemónicos a nivel mundial. Valores, prácticas de consumo y estilos de vida se han transmitido gracias a la publicidad, la televisión, el cine, internet, la familia, la escuela y las múltiples interacciones que todo esto ha generado. Se fue gestando una cultura del entretenimiento, de lo superfluo y del individualismo donde principalmente la televisión educó para el consumo de determinadas formas de entender la vida en sociedad.

A partir de finales de los años setenta del siglo pasado, se produjo una aceleración de los cambios anteriores a partir de la expansión de la microelectrónica, de los automatismos y de la informática, que ha dado lugar a nuevos medios de comunicación, robots y ordenadores. Todos los cambios económicos, sociales y tecnológicos que han sucedido a partir del nacimiento de la sociedad de consumo, nos han llevado a la nueva etapa, en la que nos encontramos. Las tecnologías de la información y de la comunicación han dado lugar a la sociedad de la información que ha privilegiado, entre otras cosas, a una nueva forma de ser y estar en el mundo. 
Como afirma Cortina (2003) si bien desde la emergencia de la producción y el consumo masivo en la década de 1920 puede hablarse de sociedades de consumo es con la sociedad de la información que se genera un acceso ininterrumpido a los objetos y servicios del mercado. En esta era del acceso en el que a través de las distintas redes de consumo se llega a todos los lugares del mundo, ha quedado subordinado el tiempo humano al universo comercial de esta era del consumo. Señala en este sentido que la creencia social más extendida en las sociedades de consumo ha sido y es la promesa de felicidad a través de la acumulación de bienes de mercado.

Para Castells (2000) en las últimas décadas del siglo XX se gestó un nuevo modo de producir, comunicar, gestionar y consumir que responde al reacondicionamiento de un sistema capitalista atravesado por un nuevo paradigma tecnológico articulado en torno a las tecnologías de la información, la economía global y la cultura digital de la era de la red. La sociedad de esta época que se caracteriza por el cambio constante es moldeada profundamente por un nuevo medio tecnológico global que funciona a tiempo real a escala planetaria. El nuevo sistema de comunicación transformó la cultura y todos los procesos colectivos e individuales son influenciados por una revolución tecnológica de alcance global.

Para Hobsbawm (1998) la ideología del progreso sustentada conceptualmente en el dominio de la naturaleza, en una tecnología revolucionaria transformadora de la vida cotidiana y en la instalación social de lo nuevo como lo mejor, dio lugar a un ser humano imprescindible para el sistema económico en tanto consumidor de bienes y servicios. Advierte que este progreso notable que ha multiplicado notoriamente la producción de manufacturas en la segunda mitad del siglo XX ha erigido como valor preponderante el individualismo asocial y el egocentrismo que busca la propia satisfacción del sujeto en sociedades ya erosionadas en sus soportes tradicionales.

Frieden (2007) ha señalado que en las últimas décadas del siglo XX el capitalismo global se ha instalado como una realidad totalmente naturalizada en la vida cotidiana y en las relaciones internacionales. Las importantes innovaciones en los transportes y las comunicaciones transformaron ostensiblemente la economía y la cultura global generando una red que integra a los consumidores, los fabricantes, los inversores, los comerciantes, los agricultores y en definitiva a todos los actores que forman parte del capitalismo global. En este nuevo universo las tecnologías, las modas y los movimientos 
artísticos simultáneamente son conocidos en todo el mundo y los beneficios relacionados a la libertad de elección de productos tecnológicos son parte de los argumentos de quienes defienden la integración global.

La revisión bibliográfica sobre la cultura de consumo global en la actual era planetaria señala que la misma ha generado transformaciones considerables en la vida cotidiana, principalmente en las zonas urbanas. Se presenta como parte de un modelo de desarrollo capitalista que privilegia el consumo depredador, irresponsable y superfluo como marco referencial para la vida.

El desarrollo ininterrumpido del complejo técnico-económico-industrial-capitalista de nuestra civilización implica un crecimiento continuo de las necesidades y los deseos suscitados por el binomio producción/consumo. A pesar de comportar zonas de pobreza y subconsumo, nuestra civilización, con el apoyo de las tentaciones publicitarias y de otro tipo, fomenta el hiperconsumo (Morin, 2011, pág. 225).

Si bien el consumo debe vincularse con la propia evolución histórica del ser humano en la sociedad, la característica central de la sociedad de consumo es que este -el consumoes una necesidad creada artificialmente, en tanto es una condición para el funcionamiento del orden económico imperante, basado en la permanente producción de bienes, servicios y experiencias para el disfrute de las cada vez más sociedades globales.

Aunque contiene zonas de pobreza y de subconsumo, nuestra civilización estimula el consumismo, espoleado por la obsolescencia rápida de los productos, el fomento del usar y tirar en detrimento de lo duradero, la sucesión acelerada de las modas, la incitación permanente a lo nuevo, la preocupación individualista por el estatus o standing, así como las frustraciones psicológicas y morales que hallan un consuelo pasajero en la compra y el abuso de bebidas, alimentos, objetos y gadgets (Morin, 2011, págs. 225-226).

En las últimas décadas, la profunda reestructuración del capitalismo produjo todo un modelo de consumo sustentado en la mercantilización de todas las cosas. La propagación de la cultura de consumo global se ha convertido en la máxima expresión de la vida cotidiana en tanto se ha instalado la idea de que el consumo es el camino para la realización de los proyectos individuales.

Schwartz (2016) señala que en las sociedades modernas occidentales la vida se presenta como una cuestión de elegir y maximizar la libertad individual para alcanzar un mayor bienestar. Al tener una impresionante variedad de objetos de consumo se ha instalado la idea de que se trata de maximizar la elección para maximizar la libertad que proporcione 
el bienestar tan anhelado. Pero al tener tantas expectativas por la gran cantidad de productos disponibles aumentan las posibilidades de experimentar la sensación de culpa por una mala elección. Este escenario es reforzado por los múltiples estímulos publicitarios que ha logrado que las personas estén atendiendo simultáneamente múltiples oportunidades de consumo con la correspondiente sensación de estar siempre perdiéndose de algo. Las personas buscan placer a través del consumo de objetos nuevos y de la ampliación de las posibilidades de elección lo que termina por convertirse en una tiranía de la elección.

El hipercapitalismo, fuerza motriz de la mundialización económica; la hipertecnificación, grado superlativo de la universalidad técnica moderna; el hiperindividualismo, que materializa la espiral del átomo individual ya liberado de las ataduras comunitarias a la antigua; el hiperconsumo, forma hipertrofiada y exponencial del hedonismo comercial. Estas lógicas en interacción incesante componen un universo dominado por la tecnificación universal, la desterritorialización acelerada y la comercialización exponencial planetaria. En estas condiciones es donde la época ve triunfar una cultura globalizada o globalista, una cultura sin fronteras cuyo objetivo no es otro que una sociedad universal de consumidores (Lipovetsky, 2010, pág. 34).

El hipercapitalismo tiene en la hipertecnificación uno de los soportes más importantes para la reproducción de la sociedad de consumidores. Las tecnologías han invadido la vida cotidiana y transformado el trabajo, el ocio, el confort y la dependencia social hacia todas las novedades y soluciones que promete el nuevo universo tecnológico. La tecnociencia define la producción, el consumo y los actuales estilos de vida .

Delgado (2011a) advierte en este sentido que el gran desarrollo científico y tecnológico ha transformado los modos de ser y pensar en la sociedad contemporánea a escala planetaria. Este desarrollo iniciado con las dos primeras revoluciones industriales y profundizado desde mediados del siglo XX ha instalado la idea hegemónica de lo nuevo como patrón dominante de la vida cotidiana. La cada vez mayor capacidad depredadora del ser humano está relacionada con los flujos constantes de información, modos de hacer y artefactos que han hecho sufrir modificaciones notorias en los modos de vivir.

La vida cotidiana se subvierte mediante la destrucción de las formas de vida y la instrumentación de un modo material único de realización de la vida. La subversión material de la vida cotidiana por los productos del conocimiento y la tecnología ha 
conducido a la mejora de las condiciones de vida de una parte significativa del mundo, pero este no es el único resultado. La estandarización de la vida humana y la pérdida de la sociodiversidad son resultados igualmente notables, aunque absolutamente destructivos e indeseables. La cotidianeidad subvertida tiende a hacerse única y dependiente de elevados consumos de naturaleza, lo que incrementa su fragilidad. La pérdida acelerada de la sociodiversidad parece una carrera desenfrenada en busca de estados sociales de homogeneidad y equilibrio. (Delgado, 2011a, págs. 21-22).

Mitcham (1989) ha sido muy preciso al advertir de los impactos sociales, culturales y ambientales por los desarrollos científico-tecnológicos que han tenido lugar en las últimas décadas del siglo XX. Esto ha dado lugar a una serie de interrogantes relacionadas con el significado de la tecnología y con las múltiples dimensiones de la vida en los que indudablemente interfiere. Como consecuencia de la gran capacidad que tiene el ser humano de transformar la realidad, a partir de su gran desarrollo tecnocientífico, la ética ha expandido sus fronteras y el sentido de la responsabilidad.

Delgado (2011 b) ha sido muy claro al afirmar que en la segunda mitad del siglo XX las sinergias entre vida cotidiana, ciencia y tecnología han sido tan significativas que han influido notablemente en los cambios sociales. Los procesos productivos, el consumo y la vida cotidiana están profundamente definidos por la tecnología.

Las reflexiones de Delgado (2011 a, 2011 b) y de Mitcham (1989) permiten problematizar sobre la cultura de consumo global y las transformaciones que la tecnología ha generado en la vida cotidiana. Las transformaciones generadas han creado una nueva sociedad adoradora de los artefactos tecnológicos y de los entornos virtuales que disciplinan para el consumo.

Delgado (2011a) entiende que la depredación de la naturaleza y la unificación de las subjetividades han sido posibles gracias a la ideología del industrialismo quien ha convertido totalmente inarmónica la relación con la naturaleza. Esta ideología ha naturalizado el consumo, la dependencia de los artefactos tecnológicos y la vida en los entornos virtuales que educan para la naturalización de los procesos humanos dependientes del tecnoconsumo.

La ideología del consumismo, sostiene Cahill (2001), ha logrado posicionarse de forma hegemónica a nivel global y se expresa como ideario superior para las poblaciones del mundo lo que ha significado la entronización de los estilos de vida privatizados. El gran desarrollo tecnológico y la publicidad como soporte de los actuales patrones de consumo 
hace insostenible el mundo para las próximas generaciones y estimula los procesos de individualización como modelo de las sociedades actuales.

En el mismo sentido Mitcham (2012) sostiene que la tecnología tiene mucho que ver con los grandes problemas y desafíos que presenta la humanidad en este siglo XXI y que amerita una valoración acerca de la condición tecnohumana en la que se desarrolla nuestra existencia. Tanto la contaminación medioambiental, la pérdida de la biodiversidad o el exceso de la información y la realidad virtual son consecuencia del uso que la humanidad ha hecho del poder tecnológico.

Cupani (2018) ha afirmado recientemente que la sociedad occidental de los siglos XX y XXI ha universalizado el concepto de la eficiencia como la mejor forma de desarrollar la vida en sociedad ya que es presentado como sinónimo de progreso, libertad, rapidez y racionalidad. La tecnología y la racionalidad sostienen la creencia de que vivimos por y para el progreso, aumentando nuestra dependencia de los artefactos modernos.

Esto quiere decir que la tecnología tiene distintos rostros y que puede ser tanto un instrumento de poder y destrucción como también útil para vivir mejor. Su uso en la vida de las personas responde cada vez más a los trucos propagandísticos, comerciales o políticos que la presentan dotada de una serie de valores asociados a lo hermoso, lo eficiente, el placer y por lo tanto lo necesario dado que se entiende que es todo lo deseado por las personas. Las personas se comportan como usuarios semivoluntarios y dependientes de artefactos y sistemas de inteligencia.

La actual cultura de consumo global es un fenómeno transcultural que sedimenta sus valores a escala global reconfigurando el sentido y la experiencia de la vida. Morin (1999 (a y b), 2003, 2006, 2015) ha expresado que la ciencia y la tecnología han transformado profundamente la vida cotidiana y que los parámetros esenciales del desarrollo actual han conducido a una crisis cultural y sistémica global. El imperio del mercado, el consumismo, el capitalismo desenfrenado y la erosión de los valores han transformado la vida social y la naturaleza instalando una crisis civilizatoria sin precedentes.

En la misma dirección, Delgado (1999) alerta sobre los grandes problemas ecológicos como fruto de los sistemas productivos que se relacionan de una forma depredadora con la naturaleza. Sostiene que el deterioro ambiental refleja el estilo de vida moderno sustentado en la racionalidad capitalista y la lógica del beneficio inmediato como valor supremo. 
La cultura de consumo global definida por Zamora (2012) como la confluencia de múltiples y nuevas experiencias, nuevos modos de nombrar y representarnos el mundo del consumo y las distintas maneras de entendernos a nosotros mismos, ha generado profundas transformaciones en las prácticas de consumo y los estilos de vida.

Lipovetsky y Serroy (2010) también han definido a la actual cultura de consumo como una hipercultura universal diseñada por el capitalismo y que tiene un sistema de valores y metas inseparables de la industria comercial, impregnando todas las actividades humanas y reconfigurado el mundo en que vivimos, expresándose principalmente mediante el hiperconsumo, el hiperindividualismo y la hipertecnología. Es la era de un consumo cargado de imágenes y de una cultura que unifica el planeta mediante la globalización mercantil de todas las cosas. Esta cultura planetaria transforma las relaciones entre las personas y de éstas con el entorno, afectando todas las dimensiones de la vida y socavando profundamente las tradiciones que ordenaba a las sociedades.

La denominada "cultura mundo" (Lipovetsky, 2010) se propaga por todas las zonas urbanas principalmente mediante las "catedrales de consumo" (Ritzer, 2000) difundiendo una serie de ideales con pretensiones de universalidad que impactan considerablemente estimulando el consumo material y simbólico, reforzando la adhesión a una cultura del desecho que ha hecho del use y tire una expresión cotidiana e instalando el consumo como "sentido de vida" (Moulian, 1998).

La cultura de consumo global manifestada como nunca antes en los entornos virtuales se ha convertido en el marco de referencia por excelencia para las actuales sociedades.

El triunfo del hipercapitalismo no es solo económico, también lo es cultural: se ha convertido en el esquema organizador de todas las actividades, el modelo general de actuar y de la vida en sociedad. Se ha apoderado del imaginario, de los modos de pensar, de los fines de la existencia, de la relación con la cultura, con la política y con la educación (Lipovetsky \& Serroy, 2010, págs. 41-42).

Se desprende que la cultura del hipercapitalismo ha diseñado una serie de dispositivos ideológicos para la construcción de una concepción del mundo centrada en el consumismo como mecanismo de dominación social. Al modelar los comportamientos, los gustos, los valores y las expectativas sociales se termina construyendo una cosmovisión centrada en el consumismo y la mercantilización de la vida misma.

Emplear la expresión cultura de consumo es subrayar que el mundo de los bienes y sus principios de estructuración son fundamentales para comprender la sociedad 
contemporánea. Ello supone centrarse en dos puntos: primero, en la dimensión cultural de la economía, en la simbolización y el uso de bienes materiales como comunicadores, y no solo como utilidades y, segundo, en la economía de los bienes culturales, en los principios de mercado de la oferta, la demanda, la acumulación de capital, la competencia y la monopolización que operan dentro de la esfera de los estilos de vida, los bienes y las mercancías culturales (Featherstone, 1991, pág. 144).

Para Bauman (2004) en la sociedad posmoderna los sujetos son considerados consumidores y la vida como una perpetua salida de compras en un mundo diseñado para el almacenamiento de objetos de consumo. El espacio público pasa a transformarse en una extensión del espacio privado y los individuos viven en una permanente carrera en busca de sensaciones. Bajo la dependencia del consumo aflora la idea de la libertad y la identidad como prioridades de una sociedad donde la individualización ya instalada permite la exploración permanente de un mundo cambiante y plagado de oportunidades. "El mundo está lleno de posibilidades como una mesa de buffet repleta de platos apetitosos, cuya cantidad excede la capacidad de degustación del más eximio glotón. Los invitados son consumidores, y el desafío más exigente e irritante que deben enfrentar es la necesidad de establecer prioridades: la necesidad de desechar algunas opciones y dejarlas inexploradas. La desdicha de los consumidores deriva del exceso, no de la escasez de opciones. (Bauman, 2004, pág. 69.)

Esta realidad ha generado una cultura de mercado que ha erosionado todos los parámetros éticos que limitaban su expansión y ha profundizado la idea del consumo como motor del desarrollo y como máxima expresión de la vida cotidiana.

Ampliando este concepto, Ritzer (2000) señala que las "catedrales de consumo" han creado una verdadera revolución en los medios de consumo estimulando experiencias continuas de consumo, entretenimiento y bienestar. Estas catedrales de consumo tienen en común la arquitectura, la distribución de espacios y la preparación del entorno para brindar a los ciudadanos la máxima sensación de libertad y felicidad.

Los nuevos medios de consumo se pueden considerar "catedrales del consumo"; es decir, para muchas personas poseen un encantado -y a veces sagrado- carácter religioso. Con el fin de atraer a un número de consumidores cada vez mayor, dichas catedrales del consumo necesitan ofrecer $-\mathrm{O}$, al menos, aparentar que ofrecen- unos escenarios cada vez más mágicos, fantásticos y encantados en los que consumir (Ritzer, 2000, pág. 19). 
La cultura de consumo se expresa cada vez más mediante imágenes que definen momentos ideales y accesibles a nuestras posibilidades. Cada imagen publicitaria desnuda nuestras carencias, proyecta nuestras expectativas y predispone a naturalizar cada vez más las prácticas de consumo asociadas a la realización personal.

Después del espectacular desarrollo de los medios de comunicación de masas, que en estas últimas décadas han ido trasformando el planeta en una "aldea global" conmovida por la "explosión informativa", hoy nadie duda del importantísimo papel que desempeñan en todas las esferas de la vida de la sociedad moderna. No solo son medios que llegan a todos los ámbitos y rincones del planeta, no solo son medios que permiten lograr casi la instantaneidad de la noticia, no solo han configurado una civilización que también podemos caracterizar como civilización de la imagen, sino que -y esto es lo que aquí nos interesa- son instrumentos idóneos para la dominación ideológica y cultural (Ander-Egg, 2005, pág. 145).

El marketing y la publicidad sostienen el control que se ejerce sobre las personas teniéndolos lo suficientemente estimulados para adquirir los objetos y servicios con los que conviven diariamente. La existencia de una manipulación de carácter multidimensional por parte de la publicidad y el marketing, principalmente visible en los distintos dispositivos tecnológicos usados cotidianamente, genera una sociedad preparada para integrar la idea de que el consumo en sus distintas vertientes es la herramienta para la búsqueda de la felicidad a la vez que la mejor forma de hacer frente a las carencias y las adversidades. La propia cultura de consumo construye y difunde imágenes de las carencias emocionales y materiales de las personas generando que sean los propios individuos quienes definan sus propias carencias. A la vez en los entornos virtuales se muestran los modelos sociales ideales para revertir todo vestigio de la vida asociado a situaciones de fracaso, precariedad, desencanto, incapacidad o aburrimiento.

También Paradelo (2013) expresa que la cultura de consumo capitalista es una forma de dominación y control del deseo sostenido por una manipulación comercial constante que tiene el propósito de crear un ser humano vaciado éticamente y predispuesto al consumo. Así, lo determinante es la función inmediatamente social, de intercambio, de comunicación, de distribución de los valores a través de un cuerpo de signos. El consumismo es un sistema que asegura el orden de los signos y la integración del grupo, es decir, una moral, un sistema de valores ideológicos, y, a la vez, un sistema de comunicación, una estructura de intercambio. De esta manera, y por paradójico que 
parezca, esta nueva forma de consumo se define como excluyente del goce. El goce ya no aparece en modo alguno como finalidad, como fin racional, sino como racionalización individual de un proceso cuyos fines están en otra parte. El goce definiría el consumo para uno mismo, autónomo y final, pero en el nuevo capitalismo global el individuo, aunque consume para sí mismo, no lo hace solo. Esta es la ilusión del consumidor, cuidadosamente mantenida por todo el discurso ideológico sobre el consumo. Efectivamente, hoy el goce es obligado y está institucionalizado, no como derecho o como placer, sino como deber del ciudadano. (Paradelo, 2013, pág. 30).

Cortina (2003) se refiere al homo consumens como el ser humano con capacidad de consumir día y noche en un universo globalizado y condicionado por la propaganda y por sus propios deseos. Afirma que el consumidor no es realmente soberano al consumir, pero tampoco es un esclavo manipulado por la sociedad de consumo.

Para Delgado (2011a), el consumismo se impone como ideología dominante estableciendo la centralidad de un sujeto consumidor atento a la búsqueda de la felicidad mediante la satisfacción de determinadas necesidades creadas artificialmente.

El triunfo de la ideología del consumismo cambió la idea tradicional de producir para satisfacer necesidades por la de producir para el consumo. Se transitó hacia la creación de necesidades de consumo y su consecuente satisfacción. El fenómeno, además de económico material, es ideológico y espiritual. Los conceptos, nociones y valores tradicionales fueron subyugados por la idea de una sociedad de abundancia, donde la meta de la felicidad podía ser alcanzada como bienestar sobre la base de la satisfacción de las necesidades de consumo. Sin embargo, las necesidades de consumo, a diferencia de otras necesidades humanas, no surgen, se crean. (pág. 117).

Este modelo consumista se desarrolla exponencialmente en los distintos entornos virtuales donde realmente tiene un papel vertebrador para la vida de las personas. El consumismo como ideología fundante e integradora se entiende por el desarrollo de la obsolescencia acelerada, la publicidad y el crédito.

Como señala Rabello (2001) la cultura de consumo, a partir de las imágenes propagadas por los medios, define una nueva ciudadanía donde niños, adolescentes y jóvenes se disputan los bienes de consumo a partir de la construcción de una realidad guionada por los medios de comunicación. 
"Pero podemos ver cómo las nuevas generaciones-niños y adolescentes- que no conocieron el mundo sin televisor, sin auto, sin teléfono, e incluso sin computadora, parecen mucho más gusto con estas transformaciones que asustan y angustian a las generaciones de los mayores.” (Rabello, 2001, pág. 55) La cultura de consumo construye ambientes favorables para que los procesos de socialización sean orientados por unos medios de comunicación y una publicidad cada vez más presentes en la vida cotidiana. Los valores, creencias y prácticas de consumo de las personas se muestran cada vez más definidas a partir de los mandatos sociales creados por todos los medios de consumo.

"La cultura de consumo, apoyada en las imágenes vehiculizadas por los medios, donde los anuncios y propagandas de productos integran nuestra cotidianeidad, desencadenó un proceso por el cual el lugar del niño y del joven en la cultura fue redefinido, originando nuevas prácticas culturales que confrontan la posición social que el niño ha ocupado en la sociedad moderna. (...) La publicidad consumista, a fuerza de buscar nuevos compradores, desmontó la visión de que los niños y jóvenes deberían esperar un tiempo posterior para integrarse a la dinámica social; así, empujó a los niños y los jóvenes al escenario social, tornándolos consumidores.” (Rabello, 2001, pág. 60).

En un contexto global de consumo la creación de las necesidades resulta fundamental para el mantenimiento del sistema. La naturalización en la vida cotidiana de la publicidad facilita la creación de una sociedad de consumidores.

La función de la publicidad y la propaganda que acompaña la expansión del comercio tiene en el nivel implícito una connotación ideológica, política y cultural: configurar el carácter social o personalidad básica de los hombres y mujeres de la sociedad de consumo. Esto ayuda, asimismo, al mantenimiento y funcionamiento del sistema. Con la venta de muchos productos se vende un estilo de vida, es decir, se venden valores culturales. Publicidad-propaganda-sociedad de consumo son elementos indisolubles: la publicidad no solo crea la demanda de bienes que satisfacen necesidades, sino que crea además pseudonecesidades hasta llegar al consumo por el consumo mismo (Ander-Egg, 2005, pág. 48).

Han $(2012$, 2013, 2014) define con precisión la existencia de una sociedad porno, del espectáculo y de rendimiento en la que las cosas se han mercantilizado y visibilizado como nunca antes para tener valor y ser consumidas. Señala que en esta sociedad el consumidor compra todo lo que le gusta de acuerdo al mandato ideológico hegemónico de este siglo XXI. Esta sociedad de rendimiento estimula el poder hacer, el exceso de 
positividad y la libertad para que el ser humano se explote cada vez más y siga siendo parte de un exceso de estímulos, informaciones e impulsos que potencien su rendimiento y sus inclinaciones consumistas.

En la sociedad expuesta, cada sujeto es su propio objeto de publicidad. Todo se mide en su valor de exposición. La sociedad expuesta es una sociedad pornográfica. Todo está vuelto hacia fuera, descubierto, despojado, desvestido y expuesto. (Han, 2013, pág. 29). Expresa este autor que, en la sociedad de los gimnasios, torres de oficinas, bancos, aviones, grandes centros comerciales y laboratorios genéticos, el ser humano se transforma en un sujeto de rendimiento influenciado por ese exceso de positividad que lo convierte en un individuo que queda a merced de ese exceso de positividad y de los múltiples estímulos del mercado. Termina convirtiéndose también en un objeto mercancía que legitima la explotación voluntaria de sí mismo.

La coacción de la exposición conduce a la alienación del cuerpo mismo. Este se cosifica como un objeto de exposición al que hay que optimizar. No es posible habitar en él. Hay que exponerlo, y con ello explotarlo. Exposición es explotación. (Han, 2013, pág. 30).

El cuerpo y la exposición se convierten en la imagen misma de una cultura de consumo insaciable y ordenadora de los más importantes rituales cotidianos.

La cultura dominante incluye un combo donde la visibilidad personal aumenta sin parar y una profusa tendencia a la producción de imágenes que construye ese universo que aúna espectáculo, exhibicionismo y voyerismo. Embarcados en imperativo tipo "exhibo, luego existo" la hipercomunicación hace las veces de soporte absoluto de toda la vida personal, como tal tiene carácter de dogma, un impulso hacia una supuesta sinceridad total y sin restricciones (Hazaki, 2019, pág. 69).

En esta nueva era del consumo global las tradiciones, los sistemas de referencias y los estilos de vida están cambiando profundamente. Para Schwab (2016) se está produciendo una transformación profunda y multidimensional de la humanidad motivada por la nueva revolución tecnológica que está cambiando la forma de vivir, trabajar, divertirnos y relacionarnos con el entorno y con nosotros mismos. Señala que esta transformación paradigmática impulsada por la revolución tecnológica está cambiando el contexto económico, social, cultural y humano en el cual tiene lugar la vida. Su evolución a un ritmo exponencial, su amplitud, los nuevos desarrollos tecnológicos y la interacción de los dominios físicos, digitales y biológicos la distingue de las revoluciones anteriores. 
Este impresionante cambio cultural ha hecho que la vida privada de las personas se abra a la exposición de los múltiples dispositivos manejados cotidianamente que funcionan con las interacciones en línea propias de las redes sociales.

Estas nuevas transformaciones pueden generar más opciones de trabajo, ocio, entretenimiento y navegación por el vasto universo de internet a la vez que reforzar los dispositivos establecidos para el consumo. También puede llegar a ahondar los actuales procesos de desigualdad social en tanto se agranda cada vez más la brecha entre quienes pueden acceder a trabajos mejor remunerados y quienes siguen ocupando los puestos más precarios cuando no engrosando las filas de los desempleados. Lo que parece seguro es que los sectores populares encontrarán en los espacios virtuales un bálsamo para el olvido momentáneo de sus problemas y miserias a la vez que un tiempo para vivenciar parte de la cultura de la felicidad hegemónica reinante.

Las tecnologías digitales entonces, parecen profundizar la brecha digital no solamente entre generaciones sino también entre los distintos sectores sociales, lo que expresa en definitiva una de las realidades más significativas de los tiempos actuales. En las sociedades globalizadas donde han sido socavadas las fronteras espacio-temporales y donde las nuevas formas de inteligencia definen los marcos conceptuales de la educación y el trabajo, los sectores populares urbanos son expulsados de un modelo de sociedad para la cual no disponen de las habilidades suficientes. Aunque parezca contradictorio la cultura de consumo global los termina integrando a través de los espacios virtuales para el ocio y la diversión.

Para Bridle (2020) la profunda aceleración tecnológica ha generado impactantes transformaciones planetarias dando lugar a una sociedad donde ya las personas no pueden pensarse ni situarse por fuera de los sistemas tecnológicos en los que están inmersos.

Sostiene Hazaki (2019) que el actual proceso de hibridación entre los seres humanos y las máquinas están generando transformaciones importantes en la condición humana, en las relaciones humanas y en el modelo de familia hegemónico. Advierte que se está en presencia de la figura del usuario-cyborg que se caracteriza por la fascinación tecnofílica, la claustrofilia y la hiperconectividad como valores centrales de su vida cotidiana. En este contexto afirma que la corriente cultural mundial hegemónica ha definido el no dormir y el consumir como dos de sus dimensiones centrales por lo que cada vez más se extiende la vigilia en un mundo más iluminado y conectado. 
El pensamiento complejo, desde la perspectiva de Morin, como forma de producción de conocimiento y marco referencial teórico, nos permite establecer nuevas relaciones complejas de la realidad observada a la vez que revisar las distintas dimensiones que caracterizan a la cultura de consumo global en los entornos virtuales. En este contexto pensar en el consumo en los entornos virtuales significa entenderlo como un fenómeno multidimensional y con interacciones sumamente complejas.

La perspectiva del pensamiento complejo para el estudio de la cultura de consumo global señala que el consumo en los entornos virtuales se presenta como una pluralidad compleja de significados, interacciones, articulaciones y relaciones que para nada se presentan de forma fragmentada. En este sentido la subversión tecnológica de la realidad es una compleja realidad que ha modificado la forma de pensarnos como seres humanos. Esto significa que si bien la subversión tecnológica de la vida cotidiana es una realidad global también lo es que la cultura de consumo global es muchas veces un medio para la realización de ritos, costumbres, tradiciones y deseos de las actuales sociedades.

\section{CONCLUSIONES}

La presente investigación ha demostrado que la cultura de consumo global como modelo vertebrador de las sociedades actuales ha generado profundas transformaciones en la vida cotidiana y en las prácticas de consumo de las actuales sociedades, subvirtiendo totalmente los modos de hacer y pensar. Desde la perspectiva del pensamiento complejo, este trabajo permitió crear nuevos marcos conceptuales para la comprensión de una cultura de consumo global que se presenta como la máxima expresión de dominación y control del sistema capitalista. Se ha naturalizado una gramática cultural sustentada en el consumismo, la mercantilización de todas las cosas y la cultura del desecho como propósito central de una existencia cada vez más desarrollada en los entornos virtuales.

El estudio de la cultura de consumo global como modelo civilizatorio regidor de la vida cotidiana es fundamental para la descripción e interpretación de las prácticas de consumo expresadas en los entornos virtuales y tecnológicos. Poder situar en perspectiva histórica las prácticas de consumo, los rituales y los estilos de vida permite una mejor comprensión de cómo la sociedad construye su relación en y con el mundo. Puede afirmarse que esta matriz cultural ha impactado profundamente en las prácticas de consumo instalándose una cultura del desecho orientadora de la vida cotidiana. Esta cultura de consumo global, en tanto regidora de la vida pública y privada, ha impactado considerablemente en los 
espacios que habitan las personas y en el sentido que le asignan a lo que hacen cotidianamente, lo que representa una nueva realidad multidimensional característica de esta era planetaria.

La vida cotidiana se ha mercantilizado y los individuos han hecho del consumismo una dimensión central en sus vidas reforzando la individualización y la hiperconectividad virtual. Es fundamental destacar que la presencia en los entornos virtuales se ha transformado en una verdadera escuela del consumo en tanto prepara a las personas para una vida signada por el perpetuo consumismo. El consumismo supera el hecho de practicar un superfluo y excesivo consumo sino que es un modo de satisfacción de las sociedades en la actual era planetaria.

La cultura de consumo diseña y transfiere modelos de felicidad, entretenimiento, placer, seguridad, bienestar, confort, visibilidad y distinción al alcance de todos con la promesa de transformar nuestras vidas en clave de felicidad. Asimismo, naturaliza la mercantilización de todas las cosas y propaga una cultura del desecho como valor universal lo que permite pensar a la cultura de consumo global como un problema multidimensional con consecuencias éticas, culturales, económicas y ambientales.

La sociedad es preparada para mirar y captar el entorno como un espacio para usar y tirar. El fundamento de esta sociedad de consumo tiene sus andamios en el uso y destrucción perpetua de los objetos y experiencias de consumo. La cultura de consumo se sostiene porque la insatisfacción de nuestros deseos lleva a una búsqueda permanente de nuevos objetos y experiencias que parecen no terminar nunca. Así, la reproducción, universalización y legitimación de la cultura de consumo global es posible por las implicaciones políticas, económicas y sociales que necesariamente debe tener para conformarse como cultura socialmente aceptada. La ideología de la cultura de consumo ordena, orienta y disciplina a las sociedades urbanas de tal forma que la mercantilización de las cosas y la cultura del desecho son una realidad en gran parte del planeta. Imágenes similares en torno al consumo pueden verse en distintos lugares del mundo lo que demuestra que a pesar de las particularidades locales una placenta mediática envuelve el planeta.

Si bien queda evidenciado el impacto de la cultura de consumo global en las prácticas de consumo la perspectiva del pensamiento complejo permite la visibilización de múltiples realidades en relación a la vida cotidiana de las personas. Las transformaciones sociales que ha generado la cultura de consumo global en las prácticas de consumo son 
multidimensionales y han cambiado la forma en que las personas construyen su vida. Los espacios urbanos de la ciudad reflejan los modelos culturales propagados por la democratización del consumo y la cultura del desecho evidenciando cada vez con mayor notoriedad que la cultura de consumo global opera como esquema organizador de la vida social y privada.

Debe precisarse que se trata de un consumo intermitente, espaciado, del que se entra y se sale, dependiendo muchas veces de la propia realidad de las personas, de los valores a los que adhieran y de otros factores que inciden en que las prácticas de consumo puedan adquirir rasgos diferentes según el contexto en el que tengan lugar. Entonces debe tenerse presente que, si bien los imperativos de la cultura de consumo transforman profundamente las prácticas y los estilos de vida, se integran también a otras realidades que también son importantes en la vida de las personas y que tienen que ver con los saberes, las tradiciones familiares, las costumbres y por supuesto con las expectativas y valores de cada persona.

\section{REFERENCIAS BIBLIOGRÁFICAS}

Ander-Egg, E. (2005). “El proceso de globalización en la cultura.”, Cuadernos Patrimonio Cultural y Turismo, (13), págs. 141-164.

Appadurai, A. (2001). La modernidad desbordada. Dimensiones culturales de la globalización.BUENOS AIRES Argentina: Ediciones Trilce, Fondo de Cultura Económica.

Bauman, Z. (2004). Modernidad líquida. Buenos Aires: Fondo de Cultura Económica.

Bauman, Z. (2007). Vida líquida. Buenos Aires: Ediciones Paidós.

Bauman, Z. (2010). Mundo consumo. Ética del individuo en la aldea global. Barcelona: Paidós.

Bauman, Z. (2011a). Daños colaterales. Desigualdades sociales en la era global. México: Fondo de Cultura Económica.

Bauman, Z. (2011b). Trabajo, consumismo y nuevos pobres. Barcelona: Gedisa.

Bridle, J. (2020). La nueva edad oscura. La tecnología y el fin del futuro. Barcelona: Debate. 
Cahill, M. .The Implications of Consumerism for the Transition to a Sustainable Society. Social Policy\& Administration ISSN 0144-5596. Vol.35, No5, December 2001, pp 627-639

Cortina, A. (2003). Por una ética del consumo. La ciudadanía del consumidor en un mundo global. Montevideo: Taurus-Universidad Católica del Uruguay

Cupani, A. (2018). Sobre la dificultad de entender filosóficamente la tecnología. ArtefaCToS. Revista De Estudios Sobre La Ciencia Y La Tecnología, 7(2), 127144

Delgado, C. (comp.) (1999). Cuba verde. En busca de un modelo para la sustentabilidad en el siglo XXI. La Habana: Editorial José Martí.

Delgado, C. (1999). "La educación ambiental desde la perspectiva política", 81-87. En: Cuba verde. En busca de un modelo para la sustentabilidad en el siglo XXI. Selección, compilación y edición científica: Carlos Jesús Delgado Díaz. La Habana: Editorial José Martí.

Delgado, C. (2011a). Hacia un nuevo saber. La bioética en la revolución contemporánea del saber. La Habana: Publicaciones Acuario, Centro Félix Varela.

Delgado, C. (2011b). Tecnología, meta-tecnología y educación. Sophia, No11, 31-55.

Featherstone, M. (1991). Cultura de consumo y posmodernismo. Buenos Aires: Amorrortu Editores.

Han, Byung.-Chul. (2012). La sociedad del cansancio. Barcelona: Herder Editorial.

Han, Byung-Chul B.-C. (2013). La sociedad de la transparencia. Barcelona: Herder Editorial.

Han, Byung-Chul B.-C. (2014). En el enjambre. Barcelona: Herder Editorial.

Hazaki, C. (2018). “Incertidumbre y felicidad cyborg”, Revista Topía , N. o( 82), 8-9

Hazaki, C. (2019). Modo Cyborg. Niños, adolescentes y familias en un mundo virtual. Buenos Aires: Topía Editorial Editorial.

Hobsbawm, E. (1998). Historia del siglo XX. Buenos Aires: Crítica

Lipovetsky, G. (2010). La felicidad paradójica. Barcelona: Anagrama.

Lipovetsky, G. (2012). El crepúsculo del deber. La ética indolora de los nuevos tiempos democráticos. Barcelona: Anagrama.

Lipovetsky, G. (2010). La felicidad paradójica. Barcelona: Anagrama. 
Lipovetsky, G.\&; Juvin, H. (2011). El Occidente globalizado. Un debate sobre la cultura planetaria. Barcelona: Anagrama.

Lipovetsky, G. \&; Serroy, J. (2010). La cultura-mundo. Barcelona: Anagrama.

Mitcham, C. (1989). ¿Qué es la filosofía de la tecnología? Barcelona: Anthropos.

Mitcham, C. (2012). "La tecnología y el peso de la responsabilidad", en libro Valores y ética para el siglo XXI. Madrid: T.F. Editores.

Morin, E. (1981). El Método 1. La naturaleza de la Naturaleza. Madrid: Ediciones Cátedra.

Morin, E. (1999a). Introducción al pensamiento complejo. Buenos Aires: Gedisa.

Morin, E. (1999b). Los siete saberes necesarios para la educación del futuro. París: UNESCO.

Morin, E. (2002a). La cabeza bien puesta. Repensar la reforma. Reformar el pensamiento. Buenos Aires: Ediciones Nueva Visión.

Morin, E. (2002b). Estamos en un Titanic. Observatorio Social. www.observatoriosocial.com.ar,6-9.

Morin, E. (2003). “¿Sociedad mundo o imperio mundo? Más allá de la Globalización y el Desarrollo", Gazeta de Antropología, N. ${ }^{\circ}(19), 1-9$.

Morin, E. (2006). Tierra Patria. Buenos Aires: Ediciones Nueva Visión.

Morin, E. (2007). Complejidad restringida y Complejidad generalizada o las complejidades de la Complejidad. Utopía y Praxis Latinoamericana, 12, Vol. 12, N. ${ }^{\circ}(38), 107-119$.

Morin, E. (2011). La vía para el futuro de la humanidad. Buenos Aires: Paidós.

Morin, E. (2015). Enseñar a vivir. Manifiesto para cambiar la educación. Buenos Aires: Nueva Visión.

Morin, Edgar; Delgado, Carlos (2016). Reinventar la educación. Abrir caminos a la metamorfosis de la humanidad. Multiversidad Mundo Real Edgar Morin. México.

Moulian, T. (1998). El consumo me consume. Santiago: Lom ediciones.

Paradelo, M. (2013). El consumo y el control del deseo como estrategias de dominación. Estudios, $\mathrm{N}^{\circ}(3), 27-44$ 
Rabello de Castro, L. (org.) (2001). Infancia y adolescencia en la cultura del consumo. Buenos Aires: Editorial Lumen.

Ritzer, G. (2000). El encanto de un mundo desencantado. Revolución en los medios de consumo. Barcelona: Editorial Ariel.

Schwab, K. (2016). La cuarta revolución industrial. Barcelona: Debate

Zamora, J. (2012). "El consumo como cultura: el imperio total de la mercancía”. Crítica, N. ${ }^{\circ}(980) 30-34$ 